\title{
Genetic Variation Amongst and Within The Native Provenances of Pinus radiata D. Don in South-eastern Australia. 2. Wood Density and Stiffness to Age 26 Years
}

\author{
By C. A. RAYMOnD ${ }^{\left.1),{ }^{*}\right)}$, M. Henson ${ }^{2)}$ and B. JoE ${ }^{3)}$
}

(Received $28^{\text {th }}$ January 2009)

\begin{abstract}
Two progeny trials of native provenances of Pinus radiata, representing the 1978 seed collection, were assessed for wood density and standing tree acoustic velocity. One trial, planted in 1980 in southern New South Wales, Australia contains all five provenances. The second trial, planted in the same region in 1982 contains only the island provenances. Results for extracted wood density, assessed from pith to bark in 5 ring segments, and standing tree acoustic velocity, measured at age 24 or 26 years, are reported.

Large differences between the mainland and island provenance were apparent for wood density and stiffness. The mainland provenances were very similar for density and followed the "normal" pattern of change with a gradual increase from the pith, followed by a plateauing around age 20. Neither of the island provenances followed this pattern of change in density: Cedros had stable density across the 4 inner most segments and Guadalupe had stable density for the inner two segments followed by a linear increase. Juvenile density was higher in both the island provenances than the mainland provenances. The island provenances differed from each other for standing tree acoustic velocity, with velocity being higher in Guadalupe provenance.

Heritabilities for wood density and acoustic velocity (average 0.37) were higher than those for tree growth and form. Across the stem radius, heritability of density was variable with some segments having zero heritabilities in some provenances, particularly Cambria, Cedros and Guadalupe. Heritability for acoustic velocity was highest for Cambria and the island provenances. Within the mainland provenances, little difference was found between populations for either wood density or acoustic velocity. Density and standing tree acoustic velocity were negatively genetically correlated with tree diameter.

Differences in provenance means were greater for acoustic velocity than for density in the outermost segment. Provenance rankings also differed, with the rankings for acoustic velocity being similar to those for density in the $2^{\text {nd }}$ segment from the bark. The genetic correlations between density and velocity reached a maximum for $3^{\text {rd }}$ segment. These results indicate that outerwood density is not the sole driver of acoustic velocity, and that the sound wave is perhaps not travelling through the outer most wood, but is penetrating some distance into the tree.
\end{abstract}

1) Centre for Plant Conservation Genetics, Southern Cross University, PO Box 157, Lismore NSW 2480 Australia.

2) Sunshine Technology, PO Box 212880 Dubai, UAE.

${ }^{3}$ ) Forests NSW, PO Box 100, Beecroft NSW 2119 Australia.

*) Corresponding Author: Dr. Carolyn Raymond. Phone +61-26620-3142, Fax +61-2-6622-2080. E-Mail: Carolyn.Raymond@ scu.edu.au
Key words: Pinus radiata, provenances, Californian collection, heritability, wood density, acoustic velocity.

\section{Introduction}

Large and consistent differences in tree growth and form exist amongst the five native provenances of Pinus radiata (D. Don) at young ages (BURDON et al., 1997) and also across the expected length of a plantation rotation (RAYMOND and HENSON, 2009). However, little is known about provenance variation and genetic control of wood quality at harvest age or changes in either provenance averages or the degree of genetic control for wood density with increasing tree age.

The five native provenances of Pinus radiata (D. Don) occur as disjunct populations along the Californian coast (Año Nuevo, Monterey and Cambria) and on two off shore islands (Guadalupe and Cedros) (LIBBY, 1997; ROGERS, 2002). The native provenances vary in size from large contiguous areas to isolated trees along ridge tops and cover a range of different soil types and different elevations with associated changes in temperature and total rainfall (Table 1) (LIBBY, 1997; MoRAN et al., 1988).

Amongst the mainland provenances, Monterey is generally considered to be the best overall for growth and Cambria the worst, with Año Nuevo the most interactive. (JoHnson et al., 1997; BuRDon et al., 1997, 1998). The two island provenances are considered inferior to the mainland provenances for growth, with Cedros being the worst provenance for survival, growth and tree form at every site where it was tested. In contrast, Guadalupe provenance, whilst slightly slower growing than the mainland provenances, appears to have good stem straightness.

In New Zealand, the Guadalupe provenance is reported to have the highest density, both for the inner 5 rings (BURDON and LOW, 1992) and across the stem at age 30 (BURDON et al., 2001), accompanied by the highest stiffness and modulus of rupture. Cedros also had high density for the inner 5 rings (BURDON and Low, 1992). In contrast, BURDON reported that the mainland provenances are very similar to each other and lower than the island provenances for both density and stiffness.

Of the three historical native provenance seed collections (see RAYMOND and HENSON, 2009 for details) the 1978 collection is the most extensively studied with provenance trials established between 1979 and 1982 at many locations in Australia, New Zealand and other countries. However, only two progeny trials were planted in Australia. The best of these trials is in New South Wales (NSW). It was established in 1980 and contains 
Table 1. - Descriptive characteristics of native provenances of Pinus radiata (from ELDRIDGe, 1978 and Moran et al., 1988).

\begin{tabular}{|l|c|c|c|c|l|}
\hline Provenance & $\begin{array}{c}\text { Latitude } \\
{ }^{\circ} \mathrm{N}\end{array}$ & $\begin{array}{c}\text { Altitude } \\
(\mathrm{m})\end{array}$ & $\begin{array}{c}\text { Rainfall } \\
(\mathrm{mm})\end{array}$ & $\begin{array}{c}\text { Area } \\
(\mathrm{ha})\end{array}$ & Soil \\
\hline Año Nuevo & 37 & $15-330$ & 800 & 450 & Sand, shaly clay loam \\
Monterey & 36.5 & $5-580$ & 400 & 3800 & Varied fertility \& base \\
Cambria & 35.5 & $30-180$ & 500 & 900 & Sandy loam, localised poor drainage \\
Guadalupe & 29 & $490-1220$ & $300 ?$ & $*$ & Rocky loam \\
Cedros & 28 & $450-610$ & $200 ?$ & 150 & Skeletal \\
\hline
\end{tabular}

* 220 trees along ridge top.

465 parents originating the mainland and island provenances with individual family identity maintained. A smaller progeny trial, containing only the island provenances, was established in the same region of NSW in 1982. These trials have been measured for growth and tree form and sampled for wood density and stiffness. Results of the growth and form assessments of the main progeny trial are reported by RAYMOND and HENSON (2009) and the wood property assessments of both these trials form the basis of the current study.

Wood density and stiffness are of commercial importance as they influence acceptability and value for a range of products. Basic density is a fundamental wood property that influences timber stiffness and strength, machinability, pulping characteristics and paper quality (Cown and KibBlewhite, 1980; BAmber and Burley, 1983; Cown et al., 1991; Roper et al., 2004). Acoustic velocity is related to structural board stiffness and grade out-turn in radiata pine (ALBERT et al., 2002; DiCKSON et al., 2004; RAYMOND et al., 2007; ROPER et al., 2004).

For radiata pine, density and stiffness vary in a radial direction within the tree (COWN and MCCONCHIE, 1980) with a cylinder of lower density, low stiffness juvenile core wood occurring in the centre, surrounded by increasingly dense and stiffer wood as the tree ages (Cown, 1980; Burdon et al., 2004). Both density and stiffness can be assessed on standing trees with pith-tobark density measured using small wood cores extracted at $1.3 \mathrm{~m}$. Stiffness (modulus of elasticity, MOE) of standing trees can be assessed using time of flight acoustic tools which measure the time taken for a stress wave to travel a known distance between probes inserted through the bark (WANG et al., 2000). However, standing tree acoustic tools are assumed to only sample the outermost wood near the bottom of the stem and can not indicate the amount or quality of core wood.

Both density and stiffness are reported as being under moderate to strong genetic control in commercial tree breeding programs (Wu et al., 2008). In these studies density was generally measured on whole pith-to-bark cores or groups of rings. When heritability is examined on a ring by ring basis, the observed changes with tree age fall into two contrasting patterns:

1) A steady increase from the pith from an initial high heritability of 0.6 or greater (KUMAR and LEE, 2002; Dungey et al., 2006, Kaingaroa site). This pattern appears to occur only for New Zealand sites
2) Low to moderate heritability (0.1 to 0.5$)$ and highly variable across the entire radius (ZAMudio et al., 2002; Li and Wu, 2005; DungeY et al., 2006, Tallaganda site). This pattern has been observed for Australian and Chilean sites.

Heritabilities are estimated from tree breeding trials which usually contain large numbers of families being tested on a single or multiple sites. It is economically unfeasible to sample all trees in all families for a range of wood properties. Generally, the maximum sample size is determined by the available budget, the number of traits to be assessed and the cost for each trait. Sampling strategies generally aim to meet one of two objectives:

- Estimation of genetic parameters such as heritability and genetic correlations, or

- Provision of phenotype data for population genetic and/or molecular marker association studies

These two objectives require different sampling strategies: estimation of genetic parameters involves calculating both between and within family components of variance and requires the sampling of multiple trees in each family. With a limited budget, a representative subset of families is usually selected and four or more trees sampled per family. In contrast, population genetics or association studies do not require a within family variance component and generally sample only a single tree from all available families. One question of statistical interest is, if you have data available from one tree from many additional families, sampled for an association genetics study, is this data of value for inclusion in genetic parameter analyses? Or will it lead to an inflation of heritability values by increasing the between family variance component? The wood sampling program for the main provenance/progeny trial covered both types of sampling strategies and provides data to test this statistical question.

The aims of this study were to determine:

- Provenance variation in wood density with age.

- Provenance variation in acoustic velocity in standing trees and its relationship to density variation within the stem.

- Genetic control of wood density and stiffness in different provenances.

- The effect on heritability estimates of increasing sample size by including trees sampled for a molecular genetics association study. 


\section{Materials and Methods}

Genetic material, field sites, growth and form assessments

Individual family seedlots, from the mainland and island provenances from the 1978 collection (ELDRIDGE, 1978), were sampled for wood density and standing tree wood stiffness from two sites. Trees sampled for wood quality in the mainland provenances were located in the 1980 provenance/progeny trial in compartment 777 of Green Hills forest, south west of Tumut (latitude $35^{\circ} 17^{\prime}$, longitude $148^{\circ} 13^{\prime}$ ) on the south western slopes of New South Wales. This trial was planted using an incomplete block design with 7 replicates each containing 23 incomplete blocks of 22 four-tree row plots with each plot being a single family. Full details of this trial, including the provenances, populations and numbers of families included plus results for tree growth and form are presented in RAYMOND and HENSON (2009). Although the island provenances had also been planted in this Green Hills trial, their survival was very limited at age 26 years due to competition effects. A separate trial containing only the island provenances had been established in 1982 in compartment 1106 of Buccleuch forest, north west of Tumut. The trial site is at approximately $700 \mathrm{~m}$ altitude, has an average annual temperature of $12^{\circ} \mathrm{C}$, average summer temperature of $27^{\circ} \mathrm{C}$, annual precipitation of approximately $1250 \mathrm{~mm}$ with a distinct winter-spring maximum. Thirty four families from Cedros provenance and 44 families from Guadalupe provenance were planted as single tree plots in a randomised complete block design. Although average survival in this trial was $39 \%$, sufficient healthy trees were available for wood sampling across a range of families.
All trees in both trials were measured for diameter over bark at $1.3 \mathrm{~m}$ above ground (DBH) in 2006 and scored for straightness ( $1=$ crooked to $6=$ straight $)$, branch angle $\left(1=\right.$ steeper than $45^{\circ}$ to $3=$ less than $45^{\circ}$, tending to flat) and nodality ( 1 = uninodal, 2 = low or uneven nodality, $3=$ moderately nodal and $4=$ highly multinodal). The Buccleuch trial was also measured for height in 2006. Based on the results of these growth and form measurements, a subsample of families was chosen from each site for wood sampling.

\section{Selection of families for wood quality assessment}

The sampling at the Green Hills site aimed to meet two different objectives: estimation of genetic parameters for wood quality and provision of phenotype data for an association genetics study. Two different sampling strategies were used, leading to two sets of data:

1) Genetic Parameter data set: 10 families were selected from each population within each provenance (see Table 2 for sampling details) and 4 trees sampled per family. A stratified sampling strategy was used with families ranked according to the breeding values for growth and the subsample of families selected to cover the range, with a slight emphasis towards the better growing end of the range. All sample trees were selected on the basis that they were healthy, straight and without obvious defects.

2) Association Study: one tree was sampled from every family of each mainland population, with the data from this tree also being included in the genetic parameter data set where appropriate. The sample trees were chosen to capture the existing family variance, with the selected tree having a breeding value for

Table 2. - Sample sizes for data sets included in genetic parameter study and association study. Total number of families and trees per provenance plus number of families from each population (Pop) within each provenance.

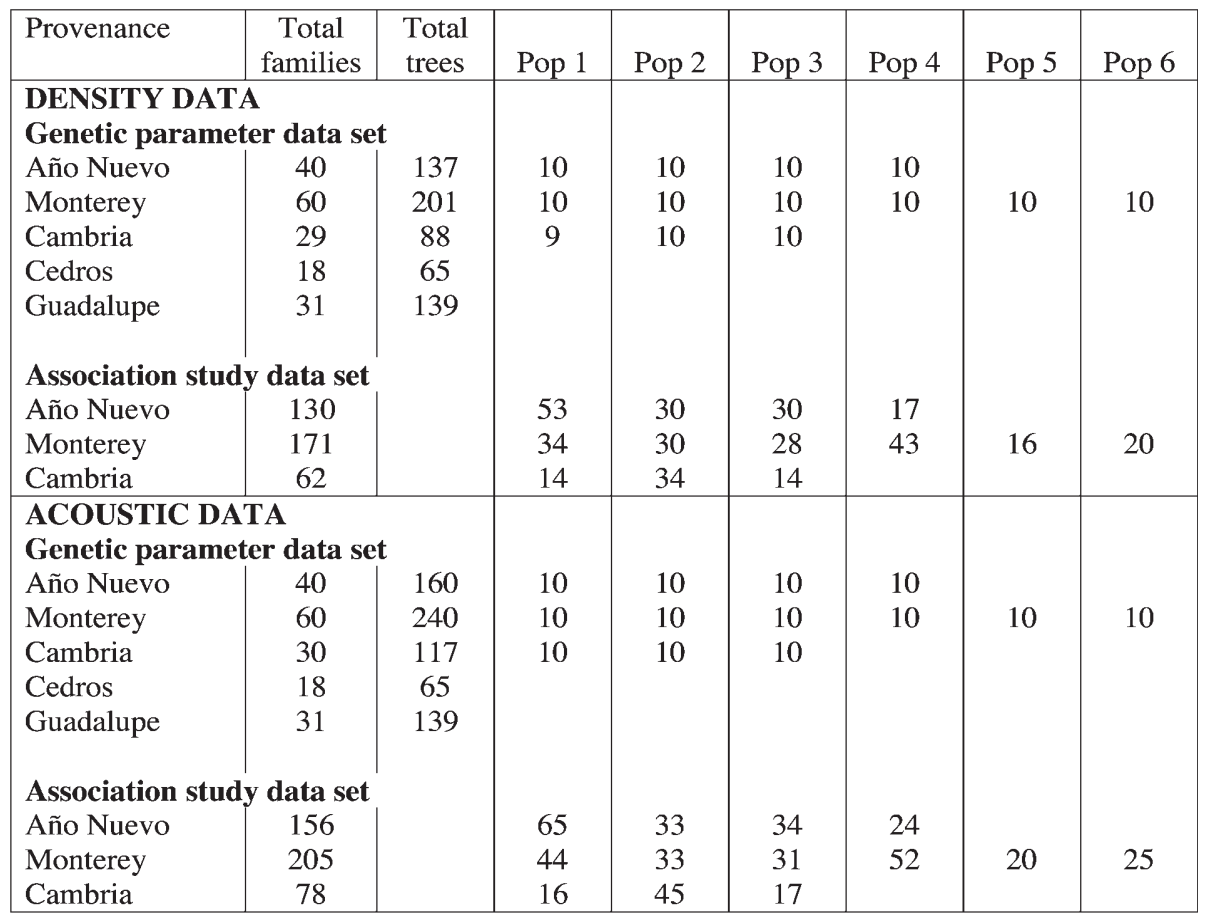


diameter as close to the family mean as possible. If the selected tree was unsuitable for wood sampling (crooked or leaning), a larger tree was selected.

The existence of these two different data sets provided the opportunity to examine the influence of sampling strategies on provenance rankings and the effect on heritability estimates of adding in the data from the additional families in the association data set. As only one tree was sampled for these additional families, it could be expected that the combined data set would have a larger between family component of variance, whilst the within family component would not change, possibly leading to an inflation of heritability values.

For the Buccleuch site, 18 families were selected from Cedros provenance, with between 2 and 4 trees sampled per family. For Guadalupe provenance, 31 families were selected and either 4 or 5 trees per family sampled.

\section{Linkage between the two sites}

Adjacent to the main provenance/progeny trial at the Green Hills site were smaller plantings of identified families from the island provenances. For five of these families there were sufficient trees surviving to allow for wood sampling. Wood samples were collected from four trees per family at Green Hills and at the Buccleuch sites and these data were used to compare tree growth and wood properties at the two sites. If no significant site effect or site by family interaction was apparent, a direct comparison of mean values for wood properties of the island provenances with the mainland provenances would be valid.

\section{Wood quality assessment}

For each sample tree a single $5 \mathrm{~mm}$ pith-to-bark core was removed at breast height $(1.3 \mathrm{~m})$, labelled and stored inside drinking straws. Each core was dissected into 5 ring segments commencing from the bark. Each segment was resin extracted and basic density determined using the maximum moisture method (SMITH, 1954).

Standing tree acoustic velocity was measured using the Fakopp time of flight tool. Probes were inserted through the bark, pointing towards each other at an angle of approximately $45^{\circ}$ to the stem, at $0.8 \mathrm{~m}$ and $1.8 \mathrm{~m}$ above ground, so that readings were centred on breast height. The stress wave is induced by striking the starter probe with a steel hammer. Time of flight was measured on both the north and south sides of each tree, averaged and velocity calculated using the flight distance of $1 \mathrm{~m}$.

\section{Data analysis}

Growth and wood quality data from the five families linking the two sites were analysed fitting a model containing site, replicate within site, family and family by site interaction. Site mean values for each trait were also plotted.

Four main data sets were analysed:

1) Mainland provenances: Genetic parameter data set with multiple trees per plot
2) Mainland provenances: Association data set with one tree per plot

3) Mainland provenances: Combination of the above 2 to see what effect adding in the extra families had on genetic parameters

4) Island provenances - data from Buccleuch site was treated as a separate data set

Initial analysis aimed to determine whether significant differences existed between the provenances and/or populations within provenances by fitting the following model:

$$
\begin{aligned}
\mathrm{Y}= & \text { mean }+ \text { Replicate }+ \text { Provenance }+ \text { Population } \\
& \text { within provenance }+ \text { Female parent }+ \text { error }
\end{aligned}
$$

with Replicate, Provenance and Population treated as fixed effects and Female as random.

Genetic parameters (and their standard errors) for each provenance and for the combined mainland provenances and combined island provenances were calculated using ASReml (GILMOUR et al., 2002) fitting a univariate model with fixed replicate and population effects and random family effects. Additive genetic covariances between pairs of traits were calculated fitting a similar bivariate model. Narrow-sense heritabilities (assuming random mating) and genetic correlations at the individual tree level were obtained from equations 1 and 2 respectively.

$$
h^{2}=\frac{\sigma_{a}^{2}}{\sigma_{a}^{2}+\sigma_{e}^{2}}
$$

Equation 1

where $h^{2}$ is the heritability, $\sigma_{a}^{2}$ is the additive genetic variance (assuming a coefficient of relationship for halfsib families of $1 / 4$ ), and $\sigma_{\mathrm{e}}^{2}$ is the residual variance.

$$
\mathrm{r}_{A x y}=\frac{\sigma_{a x y}^{2}}{\sqrt{\sigma_{a x}^{2} \times \sigma_{a y}^{2}}}
$$

Equation 2

where $r_{\mathrm{Axy}}$ is the genetic correlation between traits, $\sigma_{\mathrm{ax}}^{2}$ is the additive genetic variance of the first trait, $\sigma_{\text {ay }}^{2}$ is the additive genetic variance of the second trait and $\sigma_{\text {axy }}$ is the additive genetic covariance between the first and second traits.

\section{Results}

\section{Linkage between the two sites}

Results of the analyses of data from the linking families indicated no significant family or family by site interaction effects for any trait. Significant differences between sites were apparent for tree diameter, with trees growing at Buccleuch, the lower altitude, younger site, being $16 \%(4.5 \mathrm{~cm})$ larger in diameter than those at Green Hills. One possible reason for the smaller size of the trees at Green Hills was competition from buffer trees surrounding the plots, which had not been removed during the thinning operation across the remainder of the trial.

No significant site effect was apparent for acoustic velocity or for density in three out of five segments (Figure 1). Site differences for wood density indicated no consistent pattern, with density being comparable for all 
segments, with the exception of the outer most wood in segment A. It appears to be valid to make direct comparisons between mean values for wood properties of the island and mainland provenances for all traits except outerwood density.

\section{Comparison of provenance means}

\section{Growth and form traits}

Significant differences were apparent between the mainland provenances for diameter at $1.3 \mathrm{~m}$ and branch angle but not for stem straightness or nodality (Table 3). Diameter of Año Nuevo and Monterey were very similar for each of the genetic parameter, association study and combined data sets. Provenance means differed slightly between the different data sets but overall the ranking of provenances remained relatively constant, with Cambria always being inferior to Año Nuevo and Monterey. Trees from Cambria were significantly smaller in diameter and had poorer branching, with a lower mean value indicating a steeper branching angle. Branch angle appears to be flattest for Año Nuevo which is significantly better than the other two provenances. No significant differences were apparent between populations within the mainland provenances for any trait.

The island provenances differed significantly for tree height, with Guadalupe being taller and having better straightness. Both provenances appear to be moderately to highly multimodal and have a relatively steep branch angle. The island provenances appear similar to Cambria for branch angle but more multimodal than the mainland provenances. However, as Cedros and Guadalupe are growing on a different site to the mainland provenances, it is impossible to separate out the provenance differences from the site differences.

\section{Wood quality}

The mainland and island provenances differ in their patterns of variation for wood density from pith to bark. Density in the juvenile wood zone (inner 2 segments, D and $\mathrm{E}$ ) is highest in the island provenances and these two provenances are almost identical for density in this zone (Figure 2, Table 4). In contrast, the mainland provenances have lower juvenile density and significant provenance differences, with Monterey having the highest juvenile density. For density in the outer 3 segments and acoustic velocity the island provenances show very large differences whilst little difference was evident amongst the mainland provenances. Whether these different patterns of variability are due to site differences is not clear as only the mean values of the linking island seedlots were compared. However, the size of the differences between the mainland and island provenances would appear to indicate a real difference between the two groups.

The rate of change in density across the radius also differs between the two groups of provenances (Figure 2). For the mainland provenances, density increases rapidly from the pith and then plateaus from segment $\mathrm{C}$ onwards (Table 4). In contrast, density for the Cedros island trees remains relatively stable for the 4 innermost segments, increasing only for the outermost segment. Guadalupe has the highest density for all pith to bark segments and a very different pattern of change with density for the two inner-most segments being very similar, followed by a continual linear increase in density for the next three segments.

Acoustic velocity differed significantly for Cedros and Guadalupe but the only difference detected amongst the mainland provenances was for the association data set where Año Nuevo had the highest and Cambria the lowest velocities. Interestingly, the size of the difference in acoustic velocity $(\sim 7 \%)$ between these two provenances was greater than the difference in outerwood density $(\sim 3 \%)$. Similarly, the difference in acoustic velocity between Guadalupe and Cedros (14\%) was greater than the difference in outerwood density $(9 \%)$. If provenance mean density and velocity are compared amongst Cambria and the island provenances, differences are also apparent. Outerwood density (segment A) for Cambria is lower than either Cedros or Guadalupe but the Cambria velocity is intermediate: lower than that Guadalupe but higher than Cedros. However, density in segment B for Cambria is intermediate between Cedros and Guadalupe, matching the ranking for velocity and perhaps indicating that the sound wave is not travelling through the outer most wood.

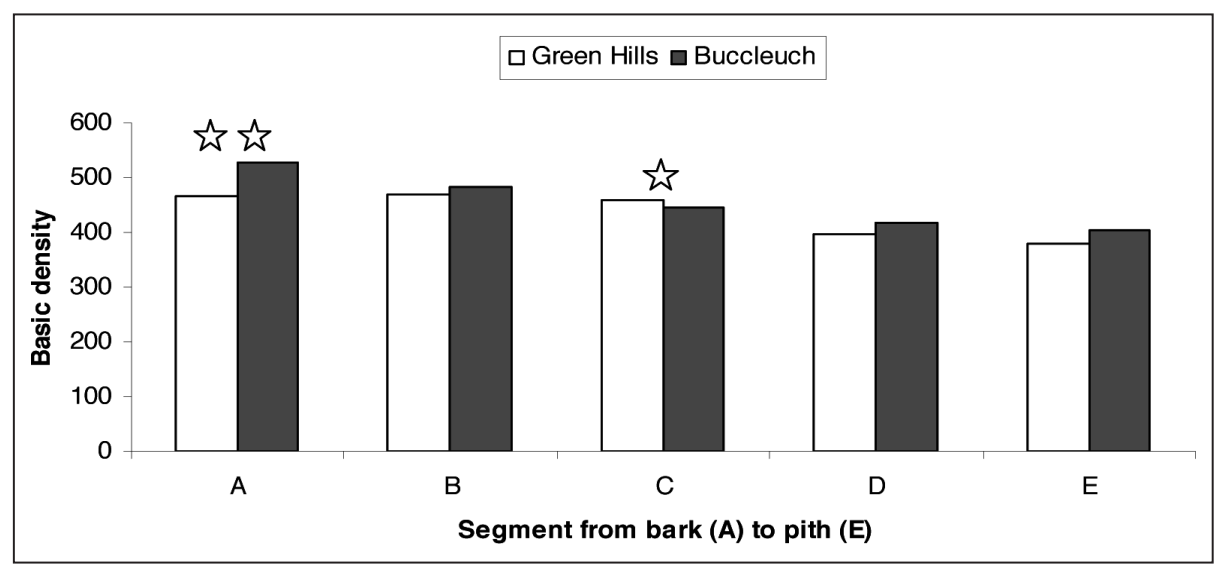

Figure 1. - Site mean values for extracted wood basic density $\left(\mathrm{kg} / \mathrm{m}^{3}\right)$ of each five ring segment from bark (A) to pith (E) of the five island provenance families linking the two sampling sites. Significance of site differences indicated by $* * p<0.01,{ }^{*} p<0.05$. 
Table 3. - Provenance means and ranks (R), standard error of differences for provenance means (SED) and significance of differences between provenances and populations for diameter over bark at $1.3 \mathrm{~m}$ (DBH), stem straightness (STR), branch quality (BRN) and nodality (NOD) for the wood sample trees.

\begin{tabular}{|c|c|c|c|c|c|c|c|c|c|}
\hline Provenance & DBH & $\mathrm{R}$ & Height & STR & $\mathrm{R}$ & BRN & $\mathrm{R}$ & NOD & $\mathrm{R}$ \\
\hline \multicolumn{3}{|c|}{ Genetic parameter data set } & & & & & & & \\
\hline Año Nuevo & 34.4 & 2 & & 3.83 & 1 & 2.25 & 1 & 2.66 & 1 \\
\hline Monterey & 34.6 & 1 & & 3.75 & 2 & 2.02 & 2 & 2.65 & 2 \\
\hline Cambria & 25.8 & 3 & & 3.64 & 3 & 1.94 & 3 & 2.45 & 3 \\
\hline Provenance & ** & & & ns & & $* *$ & & ns & \\
\hline Population & ns & & & ns & & ns & & ns & \\
\hline SED & 2.2 & & & 0.27 & & 0.16 & & 0.23 & \\
\hline \multicolumn{3}{|c|}{ Association study data set } & & & & & & & \\
\hline Año Nuevo & 31.4 & 2 & & 3.76 & 2 & 2.37 & 1 & 2.80 & 1 \\
\hline Monterey & 32.1 & 1 & & 3.85 & 1 & 2.03 & 2 & 2.73 & 2 \\
\hline Cambria & 26.0 & 3 & & 3.39 & 3 & 1.82 & 3 & 2.37 & 3 \\
\hline Provenance & $* *$ & & & ns & & $* *$ & & ns & \\
\hline Population & ns & & & ns & & ns & & ns & \\
\hline SED & 1.3 & & & 0.27 & & 0.16 & & 0.20 & \\
\hline \multicolumn{3}{|l|}{ Combined data set } & & & & & & & \\
\hline Año Nuevo & 32.2 & 2 & & 3.77 & 2 & 2.31 & 1 & 2.71 & 1 \\
\hline Monterey & 32.9 & 1 & & 3.79 & 1 & 2.06 & 2 & 2.64 & 2 \\
\hline Cambria & 26.0 & 3 & & 3.43 & 3 & 1.91 & 3 & 2.36 & 3 \\
\hline Provenance & $* *$ & & & $*$ & & $* *$ & & ns & \\
\hline Population & ns & & & ns & & ns & & ns & \\
\hline SED & 1.4 & & & 0.20 & & 0.20 & & 0.16 & \\
\hline \multicolumn{5}{|c|}{ Island provenances - all trees at Buccleuch site } & & & & & \\
\hline Cedros $(160)^{\&}$ & 28.0 & & 17.1 & 3.06 & & 1.92 & & 3.22 & \\
\hline Guadalupe (374) \& & 26.5 & & 21.6 & 3.41 & & 1.89 & & 3.35 & \\
\hline Provenance & ns & & $* *$ & $*$ & & ns & & ns & \\
\hline SED & 1.1 & & 0.5 & 0.15 & & 0.07 & & 0.15 & \\
\hline \multicolumn{9}{|c|}{ Island provenances - wood sample trees only } & \\
\hline Cedros $(65)^{\&}$ & 30.0 & & 18.1 & 3.29 & & 1.98 & & 3.23 & \\
\hline Guadalupe (139) \& & 28.4 & & 22.3 & 3.53 & & 1.93 & & 3.52 & \\
\hline Provenance & ns & & ** & ns & & ns & & ns & \\
\hline SED & 1.3 & & 0.5 & 0.17 & & 0.09 & & 0.25 & \\
\hline
\end{tabular}

$\mathrm{P}<0.05$, ** $\mathrm{P}<0.01, \mathrm{~ns}=$ not significant.

${ }^{\&}$ Number of trees sampled.

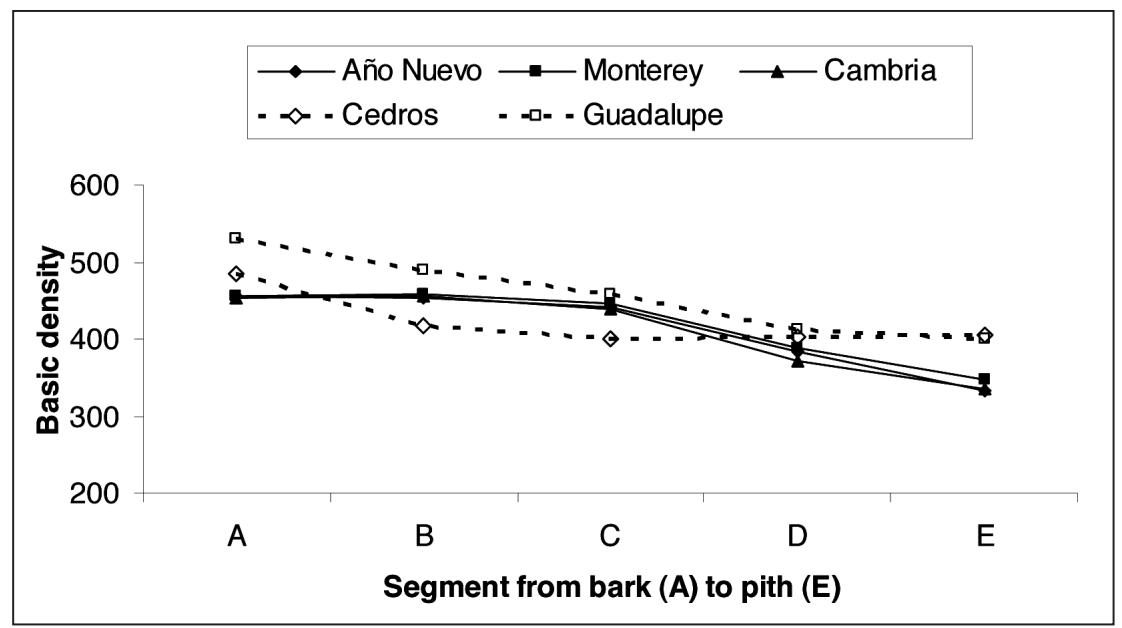

Figure 2. - Mean values for extracted wood basic density $\left(\mathrm{kg} / \mathrm{m}^{3}\right)$ of each five ring segment from bark (A) to pith (E) of the each provenance. Average standard error is $\pm 3.1\left(\mathrm{~kg} / \mathrm{m}^{3}\right)$. 
Table 4. - Provenance means and ranks (R), standard error of differences for provenance means (SED) and significance of differences between provenances and populations for extracted wood density for each 5 ring segment from the bark (A) to the pith (E) and standing tree acoustic velocity at 26 years. Tests for significance of differences plus significance differences between means (SED) presented for all provenances.

\begin{tabular}{|c|c|c|c|c|c|c|c|c|c|c|c|c|}
\hline Provenance & A & $\mathrm{R}$ & B & $\mathrm{R}$ & $\mathrm{C}$ & $\mathrm{R}$ & $\mathrm{D}$ & $\mathrm{R}$ & $\mathrm{E}$ & $\mathrm{R}$ & $\begin{array}{l}\text { Acoustic } \\
\text { Velocity }\end{array}$ & $\mathrm{R}$ \\
\hline \multicolumn{3}{|c|}{ Genetic parameter data set } & & & & & & & & & & \\
\hline Año Nuevo & 456 & 1 & 454 & 3 & 442 & 2 & 382 & 2 & 333 & 3 & 4.05 & 2 \\
\hline Monterey & 456 & 1 & 458 & 1 & 446 & 1 & 389 & 1 & 348 & 1 & 4.06 & 1 \\
\hline Cambria & 453 & 3 & 456 & 2 & 438 & 3 & 371 & 3 & 336 & 2 & 3.91 & 3 \\
\hline Provenance & ns & & ns & & ns & & * & & ** & & ns & \\
\hline Population & ns & & ns & & ns & & ns & & ns & & $\mathrm{ns}$ & \\
\hline SED & 12 & & 11 & & 12 & & 9 & & 7 & & 0.08 & \\
\hline \multicolumn{3}{|c|}{ Island provenances } & & & & & & & & & & \\
\hline Cedros & 485 & & 416 & & 400 & & 402 & & 405 & & 3.45 & \\
\hline Guadalupe & 529 & & 490 & & 459 & & 412 & & 401 & & 3.95 & \\
\hline Provenance & $* *$ & & $* *$ & & $* *$ & & ns & & ns & & $* *$ & \\
\hline SED & 9 & & 8 & & 8 & & 6 & & 7 & & 0.07 & \\
\hline \multicolumn{3}{|c|}{ Association study data set } & & & & & & & & & & \\
\hline Año Nuevo & 459 & 1 & 462 & 1 & 446 & 1 & 387 & 2 & 343 & 2 & 4.11 & 1 \\
\hline Monterey & 433 & 3 & 445 & 2 & 443 & 2 & 389 & 1 & 354 & 1 & 4.09 & 2 \\
\hline Cambria & 446 & 2 & 445 & 2 & 421 & 3 & 359 & 3 & 325 & 3 & 3.85 & 3 \\
\hline Provenance & * & & ns & & ns & & $* *$ & & $* *$ & & * & \\
\hline Population & $*$ & & $*$ & & ns & & ns & & $*$ & & * & \\
\hline SED & 11 & & 10 & & 11 & & 9 & & 7 & & 0.07 & \\
\hline \multicolumn{4}{|c|}{ Combined mainland data set } & & & & & & & & & \\
\hline Año Nuevo & 461 & 1 & 462 & 1 & 447 & 1 & 386 & 2 & 342 & 2 & 4.08 & 1 \\
\hline Monterey & 443 & 3 & 452 & 2 & 445 & 2 & 387 & 1 & 351 & 1 & 4.07 & 2 \\
\hline Cambria & 452 & 2 & 452 & 2 & 432 & 3 & 367 & 3 & 327 & 3 & 3.86 & 3 \\
\hline Provenance & $*$ & & ns & & ns & & $* *$ & & $* *$ & & ns & \\
\hline Population & ns & & ns & & ns & & ns & & ns & & $*$ & \\
\hline SED & 9 & & 8 & & 9 & & 7 & & 5 & & 0.06 & \\
\hline
\end{tabular}

${ }^{*} \mathrm{P}<0.05,{ }^{* *} \mathrm{P}<0.01, \mathrm{~ns}=$ not significant.

Comparing results across the different data sets for the mainland provenances indicates that the increased sample size for the association and combined data sets led to some changes in observed levels of significance tests and a change in ranking of the provenances for density in the inner-most segment (E), with Año Nuevo and Cambria swapping ranking, but both remaining inferior to Monterey.

\section{Comparison of populations within mainland provenances}

Little difference was apparent between populations within any of the mainland provenances for density or acoustic velocity (Tables 4 and 5). Interestingly, the ranking of populations for density in segment A was not always the same as the ranking for standing tree acoustic velocity. This is particularly noticeable in Cambria, where the highest density population for segment A had significantly lower acoustic velocity than the other two populations. However, density in segment B follows the same pattern as acoustic velocity, again indicating that perhaps the sound wave is not traveling through the outer most wood or that other anatomical characteristics or water content of the wood may be influencing velocity.

\section{Genetic parameters}

Heritabilities for tree size and straightness (Table 6) were much higher for the island provenances than for the mainland provenances. Heritabilities for all traits were similar for Año Nuevo and Monterey but much lower for Cambria, which displayed a zero heritability for tree diameter. Heritability for tree diameter and height were very similar for Cedros and Guadalupe but Cedros had lower heritabilities for stem straightness, nodality and particularly, branch angle.

Heritabilities for wood density and acoustic velocity for the genetic parameter data set (Table 7, Part A,) show some complex patterns of change both with age and across the different provenances. For Año Nuevo and Monterey, heritabilities for wood density were generally much higher than for tree size and form and were similar for most segments, increasing with tree age from segment E to B, before plateauing. However, heritability for the inner segments for these two provenances was relatively low, being 0.08 for segment $\mathrm{E}$ in Monterey and 0.19 for segment D in Año Nuevo. The high heritability of density in segments A and B in Año Nuevo (0.64 and 0.68 ) is in dramatic contrast to the zero heritability for acoustic velocity in this provenance. Similarly, the heri- 
Table 5. - Population means and ranks (R) for extracted wood density for each 5 ring segment from the bark (A) to the pith (E) and standing tree acoustic velocity at 26 years for each population in each of the mainland provenance, estimated using the combined mainland data set.

\begin{tabular}{|l|c|c|c|c|c|c|c|c|c|c|c|c|c}
\hline & & & & & & & & & & & Acoustic & \\
Provenance & Pop. & A & R & B & R & C & R & D & R & E & R & Velocity & R \\
\hline Año Nuevo & $01-1$ & 447 & 1 & 456 & 1 & 428 & 1 & 380 & 2 & 344 & 3 & 3.91 & 1 \\
& $01-2$ & 440 & 2 & 449 & 2 & 422 & 2 & 381 & 1 & 349 & 1 & 3.87 & 3 \\
& $01-3$ & 430 & 3 & 440 & 3 & 418 & 3 & 369 & 4 & 337 & 4 & 3.84 & 4 \\
& $01-4$ & 430 & 3 & 438 & 4 & 416 & 4 & 379 & 3 & 347 & 2 & 3.89 & 2 \\
\hline Significance & & ns & & $*$ & & ns & & ns & & ns & & ns & \\
\hline Monterey & $02-1$ & 444 & 6 & 446 & 6 & 441 & 4 & 382 & 4 & 350 & 1 & 4.04 & 5 \\
& $02-2$ & 457 & 2 & 451 & 3 & 441 & 4 & 373 & 6 & 344 & 4 & 4.10 & 2 \\
& $02-3$ & 449 & 5 & 447 & 5 & 437 & 6 & 381 & 5 & 343 & 5 & 4.03 & 6 \\
& $02-4$ & 450 & 4 & 451 & 3 & 448 & 2 & 383 & 3 & 342 & 6 & 4.13 & 1 \\
& $02-5$ & 460 & 1 & 456 & 1 & 445 & 3 & 385 & 2 & 348 & 2 & 4.07 & 3 \\
& $02-6$ & 455 & 3 & 456 & 1 & 449 & 1 & 390 & 1 & 348 & 2 & 4.06 & 4 \\
\hline Significance & & ns & & ns & & ns & & ns & & ns & & ns & \\
\hline Cambria & $03-1$ & 453 & 1 & 452 & 3 & 433 & 3 & 365 & 3 & 327 & 3 & 3.81 & 3 \\
& $03-2$ & 437 & 3 & 455 & 2 & 447 & 1 & 368 & 2 & 336 & 2 & 4.04 & 2 \\
& $03-3$ & 451 & 2 & 461 & 1 & 446 & 2 & 380 & 1 & 341 & 1 & 4.12 & 1 \\
\hline Significance & & ns & & ns & & ns & & ns & & ns & & $*$ & \\
\hline
\end{tabular}

${ }^{*} \mathrm{P}<0.05,{ }^{* *} \mathrm{P}<0.01, \mathrm{~ns}=$ not significant.

Table 6. - Heritabilities for diameter over bark at $1.3 \mathrm{~m}(\mathrm{DBH})$, tree height (HT), stem straightness (STR), branch angle (BRN) and nodality (NOD) for all trial trees in each provenance and for the combined mainland and island provenances separately. Heritabilities for the mainland provenances are from RAYMOND and HENSON (2009).

\begin{tabular}{|l|cc|cc|cc|cc|cc|}
\hline Provenance & DBH & se & HT & se & STR & se & BRN & se & NOD & se \\
\hline Mainland & 0.18 & 0.03 & & & 0.19 & 0.03 & 0.19 & 0.03 & 0.27 & 0.04 \\
& & & & & & & & & & \\
Año Nuevo & 0.14 & 0.04 & & & 0.13 & 0.05 & 0.27 & 0.06 & 0.32 & 0.06 \\
$\begin{array}{l}\text { Monterey } \\
\text { Cambria }\end{array}$ & 0.20 & 0.04 & & & 0.21 & 0.05 & 0.13 & 0.04 & 0.29 & 0.05 \\
& 0 & & & & 0.08 & 0.05 & 0.05 & 0.05 & 0.05 & 0.05 \\
Islands & 0.43 & 0.09 & 0.53 & 0.08 & 0.38 & 0.09 & 0.23 & 0.09 & 0.34 & 0.09 \\
Cedros & 0.39 & 0.17 & 0.46 & 0.16 & 0.28 & 0.18 & 0.04 & 0.21 & 0.12 & 0.20 \\
Guadalupe & 0.43 & 0.10 & 0.51 & 0.09 & 0.40 & 0.10 & 0.27 & 0.11 & 0.39 & 0.10 \\
\hline
\end{tabular}

tability of acoustic velocity in Monterey (0.27) is much lower than the heritability of 0.53 for density of segments $\mathrm{A}$ and $\mathrm{B}$.

The third of the mainland provenances, Cambria, has a very different pattern of change in the heritability of wood density with tree age, with heritability being zero for the inner most segment (E) and the two outer most segments (A and B). Heritability is at a maximum of 0.47 in segment $\mathrm{D}$, corresponding to ages 6 to 10 years, and also to the expected time of canopy closure. This provenance also had a zero heritability value for tree diameter, and very low heritabilities for tree form traits. In contrast, the heritability for acoustic velocity (0.41) is higher than that in Año Nuevo or Monterey and this was the only mainland provenance where significant differences were found between populations for acoustic velocity (Table 5) with population 03-1 having the lowest velocity, followed by 03-2 and 03-3.

The two island provenances differ from both the mainland provenances and from each other in their patterns of change in heritability. For both these provenances, heritability of density is zero in segment $\mathrm{D}$, which again would correspond to the expected time of canopy closure.
Heritability of density in other segments was high and similar to, or greater than, heritability for tree height (Table 6). Excluding segment $\mathrm{D}$, across the tree radius in Cedros, heritability of density is consistently high but decreased slightly from 0.61 in segment $\mathrm{E}$ to 0.54 in segment A. The reverse pattern is apparent in Guadalupe, with the heritability of density increasing from 0.20 in segment $\mathrm{E}$ to a maximum of 0.63 in segment $\mathrm{B}$, before dropping slightly to 0.53 in the outer most segment A.

In both these provenances the heritability of acoustic velocity (0.54 and 0.61$)$ is high and very similar to that for density in the outer two segments (ranging from 0.53 to 0.63 ). This is very different to the results for the each of the mainland provenances, where heritability for velocity was much lower than density in Año Nuevo and Monterey and much higher in Cambria.

The effect of increasing the sample size by adding in trees from the association study (one tree from 236 additional families for density or 309 additional families for acoustic velocity) can be determined by comparing heritabilities for the mainland provenances in parts $\mathrm{A}$ and $\mathrm{B}$ of Table 7. It was expected that this additional data would increase the between family component of vari- 
ance but would not affect the within family component as only a single tree was sampled in each family. If this occurred, then heritability estimates would be inflated. This only seems to have occurred for the lower heritability traits of density in the inner most segments D and $\mathrm{E}$ of Año Nuevo and Monterey. Very little difference is apparent for heritability estimates of density in the remaining segments or for acoustic velocity in these two provenances. For Cambria, the inclusion of additional trees appears to have had a detrimental effect on the heritability estimate for segment $\mathrm{C}$, reducing it from 0.33 to 0.10 .
Genetic correlations (Table 8) were estimated amongst the wood properties and also with tree growth and form using the mainland provenances genetic parameter data set and also for Guadalupe provenance separately. As the two island provenances were very different to each other in mean values for wood properties and patterns of genetic control, it was not considered appropriate to estimate genetic correlations across both provenances. For Cedros, the low number of families (31) sampled for wood properties was considered insufficient to allow for estimation of genetic correlations with any degree of reliability. For Guadalupe, genetic correlations with tree

Table 7. - Heritabilities for the combined mainland and island provenances and for each provenance separately for extracted wood density for each 5 ring segment from the bark (A) to the pith (E) and standing tree acoustic velocity at 26 years. Heritabilities are calculated using the genetic parameter data set (multiple trees per family) and for the total data set (genetic parameter plus association trees).

\section{A. GENETIC PARAMETER DATA SET}

\begin{tabular}{|c|c|c|c|c|c|c|c|c|c|c|c|c|}
\hline Provenance & A & se & $\mathrm{B}$ & se & $\mathrm{C}$ & se & $\mathrm{D}$ & se & $\mathrm{E}$ & se & $\begin{array}{c}\text { Acoustic } \\
\text { velocity }\end{array}$ & se \\
\hline Mainland & 0.51 & 0.09 & 0.47 & 0.09 & 0.43 & 0.10 & 0.36 & 0.12 & 0.16 & 0.16 & 0.28 & 0.11 \\
\hline Año Nuevo & 0.64 & 0.10 & 0.68 & 0.09 & 0.50 & 0.15 & 0.19 & 0.26 & 0.36 & 0.21 & 0 & \\
\hline Monterey & 0.53 & 0.12 & 0.53 & 0.12 & 0.48 & 0.13 & 0.37 & 0.16 & 0.08 & 0.27 & 0.27 & 0.16 \\
\hline Cambria & 0 & & 0 & & 0.33 & 0.31 & 0.47 & 0.22 & 0 & & 0.41 & 0.19 \\
\hline Islands & 0.53 & 0.12 & 0.61 & 0.10 & 0.41 & 0.16 & 0 & & 0.35 & 0.16 & 0.59 & 0.10 \\
\hline Cedros & 0.54 & 0.26 & 0.58 & 0.22 & 0.58 & 0.22 & 0 & & 0.61 & 0.19 & 0.61 & 0.18 \\
\hline Guadalupe & 0.53 & 0.14 & 0.63 & 0.11 & 0.38 & 0.19 & 0 & & 0.20 & 0.22 & 0.54 & 0.14 \\
\hline
\end{tabular}

\section{B. GENETIC PARAMETER PLUS ASSOCATION DATA SETS}

\begin{tabular}{|c|c|c|c|c|c|c|c|c|c|c|c|c|}
\hline Provenance & A & se & B & se & $\mathrm{C}$ & $\mathrm{se}$ & D & se & $\mathrm{E}$ & se & $\begin{array}{l}\text { Acoustic } \\
\text { velocity }\end{array}$ & se \\
\hline Combined & 0.54 & 0.08 & 0.50 & 0.08 & 0.45 & 0.10 & 0.41 & 0.11 & 0.25 & 0.15 & 0.27 & 0.11 \\
\hline Año Nuevo & 0.64 & 0.10 & 0.70 & 0.08 & 0.48 & 0.15 & 0.26 & 0.25 & 0.44 & 0.17 & 0 & \\
\hline Monterey & 0.55 & 0.11 & 0.52 & 0.11 & 0.52 & 0.12 & 0.46 & 0.15 & 0.15 & 0.25 & 0.29 & 0.16 \\
\hline Cambria & 0 & & 0 & & 0.10 & 0.46 & 0.49 & 0.20 & 0 & & 0.39 & 0.18 \\
\hline
\end{tabular}

Table 8. - Genetic correlations (and standard error) for mainland provenances genetic parameter data set plus Guadalupe provenance for extracted wood density for each 5 ring segment from the bark (A) to the pith (E), standing tree acoustic velocity, tree diameter over bark at $1.3 \mathrm{~m}(\mathrm{DBH})$, stem straightness (STR), branch angle (BRN) and nodality (NOD) at 26 years.

\begin{tabular}{|c|c|c|c|c|c|c|c|c|c|c|c|c|}
\hline Mainland & A & se & $\mathrm{B}$ & se & $\mathrm{C}$ & se & $\mathrm{D}$ & se & $\mathrm{E}$ & se & $\begin{array}{l}\text { Acoustic } \\
\text { velocity }\end{array}$ & se \\
\hline B & 0.92 & 0.06 & & & & & & & & & & \\
\hline $\mathrm{C}$ & 0.78 & 0.13 & 0.89 & 0.09 & & & & & & & & \\
\hline D & 0.96 & 0.18 & $\mathrm{~B}^{*}$ & & $\mathrm{~B} *$ & & & & & & & \\
\hline $\mathrm{E}$ & $\mathrm{B}^{*}$ & & $\mathrm{~B} *$ & & 0.62 & 0.83 & 0.39 & 0.83 & & & & \\
\hline Acoustic velocity & 0.77 & 0.20 & 0.73 & 0.20 & 0.83 & 0.20 & $\mathrm{~B}^{*}$ & & 0.41 & 0.75 & & \\
\hline $\mathrm{DBH}$ & -0.19 & 0.21 & -0.46 & 0.19 & -0.69 & 0.19 & -0.28 & 0.28 & -0.28 & 0.47 & 0.31 & 0.28 \\
\hline STR & 0.53 & 0.44 & 0.53 & 0.44 & -0.07 & 0.35 & 0.43 & 0.43 & 0.97 & 0.97 & 0.81 & 0.51 \\
\hline BRA & -0.27 & 0.42 & -0.29 & 0.42 & -0.49 & 0.49 & -0.89 & 0.64 & -0.95 & 0.99 & -0.22 & 0.55 \\
\hline NOD & 0.12 & 0.25 & 0.03 & 0.25 & -0.05 & 0.26 & 0.26 & 0.30 & -0.06 & 0.48 & 0.29 & 0.31 \\
\hline
\end{tabular}

\begin{tabular}{|l|cc|cc|cc|cc|c|}
\hline Guadalupe & A & se & B & se & C & se & D & se & E \\
\hline B & 0.98 & 0.06 & & & & & & & \\
C & 0.87 & 0.19 & 0.92 & 0.12 & & & & & \\
D & $\#$ & & $\#$ & & $\#$ & & & & \\
E & -0.60 & 0.38 & -0.65 & 0.36 & 0.20 & 0.65 & $\#$ & & \\
Acoustic velocity & 0.47 & 0.28 & 0.50 & 0.25 & 0.87 & 0.25 & $\#$ & & 0.85 \\
DBH & 0.30 & 2.14 & -0.40 & 2.22 & $\mathrm{~B}^{*}$ & & $\#$ & 0.47 \\
\hline
\end{tabular}

* B estimate is bound at limit of parameter space (1.0).

\# Heritability for density of segment D was zero so genetic correlation could not be estimated. 
form traits could not be estimated owing to problems with getting the model to convergence.

Genetic correlations between density in adjacent segments were generally very high (Table 8) for both the mainland provenances and for Guadalupe. For Guadalupe, one surprising result was the strong negative genetic correlation between density in the inner most segment (E) with density in the outer two segments A (-0.60) and B (-0.65), indicating that families with high juvenile density would have lower outer wood density than the rest of the population.

For the mainland provenances, a negative correlation existed between tree diameter and density in all segments, with this correlation being the most negative for segments B (-0.46) and C (-0.69). For Guadalupe, the correlation was negative for segment $B$ but positive for the outer most segment A, albeit with large standard errors on both estimates.

For the mainland provenances, acoustic velocity was positively correlated with tree diameter and nodality and very strongly positively correlated with stem straightness. This positive correlation between velocity and diameter is the reverse of the negative correlations of density with diameter. No significant provenance differences were apparent for stem straightness, density in the outer three segments or for acoustic velocity but were apparent for diameter (Tables 3 and 4) with Cambria being smaller, so provenance differences could be the cause of these different correlations. These genetic correlations were rerun excluding data from Cambria and correlations between diameter and density increased to -0.39 for segment $A,-0.61$ for segment $B$ and -0.81 for segment $\mathrm{C}$ whilst the correlation between diameter and acoustic velocity changed sign from 0.31 to -0.36 . So, for Año Nuevo and Monterey the negative relationship between diameter and wood density appears to be much stronger than the relationship between diameter and acoustic velocity.

Stem straightness has moderate to strong correlations with density in all segments except C. Unfortunately, for Guadalupe correlations between diameter and acoustic velocity and for wood properties with stem straightness could not be estimated owing to convergence problems.

Standing tree acoustic velocity was positively correlated with density in all segments, with the correlations being highest with segment $\mathrm{C}$ for both the mainland provenances and Guadalupe. Combined with the differences in rankings of provenances and populations for density and velocity presented above, evidence is building to make a reasonable case that the sound wave is not traveling through the outer most wood in the tree but is penetrating some distance into the tree.

\section{Discussion}

Large provenance differences were identified for wood density and stiffness, with the island provenances being distinctly different to the mainland provenances. However, the pattern of genetic architecture for wood quality differs to that observed for growth and form traits in this species. Within the mainland provenances the per- formance of Año Nuevo and Monterey for tree growth and straightness was almost identical, with Cambria being less vigorous and less straight (RAYMOND and HENson, 2009). The two island provenances, Cedros and Guadalupe, were significantly inferior to the mainland provenances for tree growth at all ages. However, for wood properties, the mainland provenances are very similar and the island provenances are distinctly different both from the mainland provenances and from each other.

For wood density, Guadalupe has the highest wood density at all ages and both Cedros and Guadalupe have higher juvenile wood density (inner 2 segments) than the mainland provenances. This confirms the superior density of the island provenances for the inner 5 rings reported by BURDON and LOw (1992). Neither of the island provenances followed the "normal" pattern of change in density with age which is a gradual increase from the pith, followed by a plateauing around age 20 (Cown et al., 1991). Cedros had remarkably little change in wood density across the 4 inner most segments (up to 20 years of age) whilst density in Guadalupe was similar for the inner two segments and then constantly increased in a linear manner. These two provenances also show significant differences for standing tree acoustic velocity, with velocity traveling faster in the higher density Guadalupe provenance.

In contrast, the mainland provenances are very similar for density at all ages and for acoustic velocity. Density variation in these provenances followed the "normal" pattern with a linear increase followed by a plateau in the outer segments. Significant differences between provenances were apparent for juvenile wood density (inner 2 segments) but the size of the difference in provenance means was less than $5 \%$ of the mean $\left(\sim 18 \mathrm{~kg} \mathrm{~m}^{-3}\right)$. In contrast, the average difference between the mainland provenances and the island provenances for juvenile density was $12 \%\left(\sim 45 \mathrm{~kg} \mathrm{~m}^{-3}\right)$. By the third segment from the pith, there is no difference apparent between the mainland provenances. Similarly, for acoustic velocity no significant difference was apparent across the mainland provenances.

Each of the mainland provenances had been divided, on an arbitrary geographic basis, into a number of populations. For tree diameter at age 26, significant differences between populations were apparent within Año Nuevo and Cambria but not Monterey. Año Nuevo also showed population differences for stem straightness. These population differences were not reflected in the wood quality data. Little difference was found between populations for either wood density or acoustic velocity, confirming the results of a New Zealand study which was based on the 1964 collection (BURDON and Low, 1992).

The island provenances, Cedros and Guadalupe, have historically been classified as different subspecies, based on morphology (LIBBY, 1997). Real genetic differences may exist between the islands and the mainland but the population size within the island provenances is also small and inbreeding is a real possibility. Based on isozyme and microsatellite data (MorAN et al., 1988; 
KARHU et al., 2006) Guadalupe is the provenance with the lowest allelic richness and expected heterozygosity, followed by Cedros. However, inbreeding appears to have minimal effect on wood density, with both WILCOX (1983) and Wu et al. (2002) reporting small, non-significant effects across a range of inbreeding levels.

RAYMOND and HENSON (2009) suggest inbreeding, combined with between tree competition effects, may have been the cause of the poor growth performance of the island provenances in the Green Hills trial. For the current study, the wood quality data for the island provenances was obtained from a different site, with 5 seedlots acting as a linkage between the sites. These linking seedlots showed no site by seedlot interactions and minimal site differences for wood properties, with the exception of density in the outermost segment. Based on the lack of a site difference, it was concluded that it was valid to directly compare the mean wood densities for the remaining segments and the acoustic velocity values of the island and mainland provenances. The lack of an apparent effect of inbreeding on wood density would appear to support this conclusion as, even if the inbreeding level is higher in the island provenances, it would not appear to be influencing the observed mean values.

Heritability estimates for tree diameter and height of the island provenances at age 26 were relatively high, with the heritability of diameter being much higher than that found for the mainland provenances, possibly due to inbreeding effects increasing the between family component of variation. Similarly, the heritability for stem straightness was also high for Cedros and especially for Guadalupe. However, it is important to note that the average survival in the Buccleuch trial of the island provenances was less than $40 \%$ and the effect of this high mortality on the heritabilities for tree growth and form is uncertain.

Heritabilities for wood density and acoustic velocity were generally much higher than those for tree growth and form, confirming results from commercial breeding programs (Wu et al., 2008). The pattern of relatively low and variable heritability for density across the radius also conformed to the pattern observed for previous Australian and Chilean studies (ZAMUDIO et al., 2002; LI and Wu, 2005; DungeY et al., 2006). However, provenance differences were evident for the age related patterns of change. Zero heritability values occurred for density in segment $\mathrm{D}$ for the island provenances and for 3 out of 5 density segments in Cambria. Canopy closure in radiata would be expected to occur between the ages of 6 and 10 years, corresponding to density segment $\mathrm{D}$ in this study. For Cambria, heritability of density is at its maximum in this segment, whilst for the island provenances heritability fall to zero.

Also occurring around this time is the rise in density from the lower levels found in the juvenile core wood to the higher mature levels. RAYMOND (2006) noted that this change in density tended to be quite rapid, occurring within a single growth ring and generally at ring seven or eight from the pith. Raymond noted that using the five ring sampling strategy tends to mask the actual age of the change. It may be that the strange heritabili- ties noted for segment $\mathrm{D}$ are related to differences between or within families in the timing of this change from juvenile to mature density. Age of transition is reported to have low to moderate $(0.13$ to 0.33$)$ heritability in four radiata progeny trials in Australia (GAPARE et al., 2006). Large site differences and a wide within-site range in transition ages (from ages 5 to 21 years) were also reported by GAPARE et al. (2006).

For Año Nuevo and Monterey, heritabilities for wood density generally follow the same pattern as the mean values: increasing with tree age from segment $E$ to $B$, before plateauing. However, heritability for the inner segments for these two provenances was relatively low. This is of interest as it is believed that the Australian and New Zealand breeding populations of radiata pine contain only these provenances (MORAN and BELL, 1987; BURDON, 1992). Within commercial breeding programs, heritabilities of less than 0.25 for individual rings, within the inner 10 rings, and particularly around ring 6, have been reported in Australia and Chile (ZAMUDIO et al., 2002; Li and Wu, 2005; DunGeY et al., 2006). Selection within breeding programs has recently been concentrating on attempting to improve juvenile wood density (segments D and E). Given the low values for heritability in these segments, the value of selecting for density prior to age 10 , is questionable. A better alternative may be to select based on density is segment C, where the heritability is much higher and density in this segment is strongly genetically correlated with juvenile density.

The heritability of density in segments A and B in Año Nuevo and Monterey are much higher than the heritabilities for acoustic velocity (zero in Año Nuevo and 0.27 in Monterey). This would suggest that other factors, such as microfibril angle, are influencing the acoustic velocity.

Although the average density of Cambria is very similar to Año Nuevo and Monterey, the heritabilities for each segment are very different. The only segment where the heritability was much larger than its standard error was segment D. Heritabilities for A, B and E were zero as was the heritability for tree diameter in this provenance. Curiously, the heritability for acoustic velocity was higher than that in the other two mainland provenances, indicating velocity is detecting strong family variability in something other than density, possibly microfibril angle. Cambria is the only mainland provenance to have significant population differences in tree diameter (RAYMOND and HENSON, 2009) and acoustic velocity. However, the ranking of the populations for tree diameter and acoustic velocity differ: population 031 had the smallest diameter trees and lowest velocity but the largest diameter trees were in 03-2 which was intermediate for velocity.

Patterns of change in heritability for the two island provenances are interesting. Both provenances had zero heritability for segment D. Excluding this segment, heritability of density is consistently high across the tree radius in Cedros, decreasing slightly from 0.61 in segment $\mathrm{E}$ to 0.54 in segment A. Guadalupe has the opposite pattern, with heritability increasing from 0.20 in segment $\mathrm{E}$ to a maximum of 0.63 in segment $\mathrm{B}$, before 
dropping slightly to 0.53 in the outer most segment A. Heritability of acoustic velocity is high for both provenances. In contrast to the mainland provenances, the heritability for velocity is similar to that for density in the outer segments, perhaps indicating that other factors such as microfibril angle are having less effect.

Guadalupe provenance has attracted interest from breeding programs due to its higher density, particularly the juvenile density. Cedros also shares this high juvenile density, but has the added advantage of a very low density gradient across most of the stem (density difference between $\mathrm{B}$ and $\mathrm{E}$ of only $11 \mathrm{~kg} \mathrm{~m}^{-3}$ ). Guadalupe also has a much lower density difference between $\mathrm{B}$ and $\mathrm{E}$ than the mainland provenances (89 vs 122,110 and $120 \mathrm{~kg} \mathrm{~m}^{-3}$ for Año Nuevo Monterey and Cambria respectively). Whether these advantages of high juvenile density and low gradient can be maintained during crosses with the mainland provenances or by introgression of the island populations into the main breeding populations would appear to be worth further exploration.

Genetic correlations between tree diameter and density were negative for all segments, following the expected pattern. Correlations between densities in adjacent segments were very high as expected. However, correlations within Guadalupe produced a surprising result, with strong negative genetic correlations (albeit with large standard errors) between density in the inner most segment $(\mathrm{E})$ and density in the outer two segments A $(-0.60)$ and $B(-0.65)$, indicating that families with high juvenile density would have lower outer wood density. For Guadalupe, the correlation of acoustic velocity was higher with density in segments $\mathrm{C}$ and $\mathrm{E}$ than it was with density in the outer two segments, indicating something strange appears to be occurring.

For the mainland provenances, stem straightness has moderate to strong positive correlations with density in all segments except C. Straightness was also strongly positive correlated with acoustic velocity. Unfortunately, for Guadalupe correlations between diameter and acoustic velocity and for wood properties with stem straightness could not be estimated due to convergence problems.

The addition of the extra trees from the association genetics study had little impact on the heritability estimates, except for a small increase in the lowest heritability traits of density in segments D and E. It was expected adding this extra data would lead to an inflation of the between family component of variance and thus an upward bias in the heritability estimate. This did not occur for most of the traits examined. One possible reason could be the relatively large number of families in the genetic parameter data set and that the additional families fell within the range already sampled, thus did not increase the between family variance. However, it is important to note that the different sampling strategies did produce some differences in both means and rankings for the mainland provenances, albeit small.

One interesting result from this study is that the differences in provenance means were greater for acoustic velocity than for density in the outermost segment (A), indicating density is not the sole driver of observed differences for acoustic velocity. Rankings for acoustic velocity and density in segment A also differed, whilst the rankings for acoustic velocity and density in segment B were the same. An example is the comparison of Cambria and the island provenances, where velocity for Cambria falls in between Cedros and Guadalupe but density in segment $\mathrm{A}$ is lower than either of the two island populations whilst segment B density is intermediate between the islands. Combined with the genetic correlations between density and velocity, which was at a maximum for segment $\mathrm{C}$, questions are raised about the actual path of the sound wave through the wood. These results suggest that the sound wave is not travelling through the outer most wood, but is penetrating some distance into the tree. The acoustic tool used in this study (a time of flight tool) detects the first occurrence of the sound wave at the receiving probe. The sound wave will take the quickest path through the wood, which would normally be expected to be the highest density wood. One possibility is that the sound wave is travelling up the heartwood boundary, where the water content of the wood is reduced and density may be increased as extractives fill the lumens.

\section{Acknowledgments}

These provenance/progeny trials were established in collaboration with CSIRO Division of Forest Research. The authors would like to thank Ian Johnson, DPI NSW, Beecroft who was responsible for the pine breeding program at this time. For the Green Hills trial, CSIRO measured height and diameter at age 3 and the age 8 measurements were done by Forests NSW and CSIRO collaboratively. The authors wish to thank Forests NSW field staff in Tumut for undertaking the age 26 assessment and especially thank KEvIN DoDDs for organizing the assessments, sorting out the maps, entering and cleaning up the data. The authors also wish to thank Dr. Josquin TiBBiTs, University of Melbourne, Creswick, for his assistance with trial maps for Green Hills and for his useful comments on this manuscript. The 2006 assessment were funded by the Radiata Pine Breeding Company, Rotorua, New Zealand.

\section{References}

Albert, D. J., T. A. Clark, R. L. Dickson and J. C. F. WALKER (2002): Using acoustics to sort radiata pine pulp logs according to fibre characteristics and paper properties. International Forestry Review 4: 12-19.

BAmBer, R. K. and J. Burley (1983): The Wood Properties of Radiata Pine. Commonwealth Agricultural Bureaux, Slough, England. 84pp.

Burdon, R. D. (1992): Genetic survey of Pinus radiata. 9. General discussion and implications for genetic management. New Zealand Journal of Forestry Science 22: 274-98.

Burdon, R. D., R. A. J. BRItTON and G. B. WALFORD (2001): Wood stiffness and bending strength in relation to density in four native provenances of Pinus radiata. New Zealand Journal of Forestry Science 31: 130-146. 
Burdon, R. D. and C. A. Low (1992): Genetic survey of Pinus radiata. 6. Wood properties: variation, heritabilities, and interrelationships with other traits. New Zealand Journal of Forestry Science 22: 228-245.

Burdon, R. D., A. Firth, C. B. Low and M. A. Miller (1997): Native provenances of Pinus radiata in New Zealand: performance and potential. New Zealand Forestry 41(4): 32-36.

Burdon, R. D., A. Firth, C. B. Low and M. A. Miller (1998): Multi-site provenance trials of Pinus radiata in New Zealand. Forest Genetic Resources 26: 3-8.

Burdon, R. D., R. P. Kibblewhite, J. C. F. Walker, R. A. Megraw, R. Evans and D. J. Cown (2004): Juvenile versus mature wood: A new concept, orthogonal to corewood versus outerwood, with special reference to Pinus radiata and P. taeda. Forest Science 50(4): 399-415.

Cown, D. J. (1980): Radiata Pine: wood age and wood property concepts. New Zealand Journal of Forestry Science 10: 504-7.

Cown, D. J. and R. P. KibBLewhite (1980): Effects of wood quality variation in New Zealand radiata pine on kraft paper properties. New Zealand Journal of Forestry Science 10: 521-532.

Cown, D. J. and D. L. McConchIE (1980): Wood property variations in an old-crop stand of radiata pine. New Zealand Journal of Forestry Science 10: 508-520.

Cown, D. J., D. L. McConchie and G. D. Young (1991): Radiata Pine Wood Properties Survey. FRI Bulletin, No. 50. Rotorua. NZ, 50 p.

Dickson, R. L., B. Joe, P. Harris, S. Holtorf and C. WiLKINSON (2004): Acoustic segregation of Australian grown Pinus radiata logs for structural board production. Australian Forestry 67: 261-266.

Dungey, H. S., A. C. Matheson, D. Kain and R. Evans (2006): Genetics of wood stiffness and its component traits in Pinus radiata. Canadian Journal of Forest Research 36: 1165-1178.

ELDRIDGE, K. G. (1978): Refreshing the genetic resources of radiata pine plantations. CSIRO Division of Forest Research, Genetics Section Report, No. 7, 120 pp.

Gapare, W. J., H. X. Wu and A. AbarqueZ (2006): Genetic control of the time of transition from juvenile to mature wood in Pinus radiata D. Don. Annals of Forest Science 63: 871-878.

Gilmour, A. R., B. J. Gogel, B. R. Cullis, S. J. Welham and R. THOMPSON (2002): ASReml user guide release 1. VSN, Hemel Hempstead, UK.

Johnson, I. G., P. K. Ades and K. G. Eldridge (1997): Growth of natural Californian provenances of Pinus radiata in New South Wales, Australia. New Zealand Journal of Forestry Science 27: 23-38.

Karhu, A., C. Vogl, G. F. Moran, J. C. Bell and O. SAVOLAINEN (2006): Analysis of microsatellite variation $\underline{\text { in Pinus radiata reveals effects of genetic drift but no }}$ recent bottlenecks. Journal of Evolutionary Biology 19: 167-175.

KumaR, S. and J. LeE (2002): Age-age correlations and early selection for end-of-rotation wood density in radiata pine. Forest Genetics 9(4): 323-330.

LI, L. and H. X. WU (2005): Efficiency of early selection for rotation-aged growth and wood density traits in Pinus radiata. Canadian Journal of Forest Research 35(8): 2019-2029.
LIBBY, W. J. (1997): Native origins of domesticated radiata pine. In: Burdon, R. D. and Moore, J. M. IUFRO '97 Genetics of Radiata Pine. FRI Bulletin No. 203. Rotorua New Zealand. pp. 9-25.

Moran, G. F. and J. C. BELL (1987): The origin and genetic diversity of Pinus radiata in Australia. Theoretical and Applied Genetics 43: 616-622.

Moran, G. F., J. C. Bell and K. G. Eldridge (1988): The genetic structure and the conservation of the five natural populations of Pinus radiata. Canadian Journal of Forest Research 18: 506-514.

RAYMOND, C. A. (2006): Density assessment of radiata pine: sampling strategy revisited. Holzforschung 60: $580-582$.

Raymond, C. A., B. Joe, R. Evans and R. L. Dickson (2007): Relationship between timber grade, static and dynamic modulus of elasticity and SilviScan properties for Pinus radiata in New South Wales. New Zealand Journal of Forestry Science 37(2): 186-196.

RAYMond, C. A. and M. Henson (2009): Genetic variation within the native provenances of Pinus radiata D. Don. I. Growth and form to age 26 years. Silvae Genetica (submitted, in review)

RoGers, D. L. (2002): In situ Genetic Conservation of Monterey pine (Pinus radiata $\mathrm{D}$. Don). Information and Recommendations. University of California, Division of Agriculture and Natural Resources, Genetic Conservation Program Report No. 26. Davis, California, USA.

Roper, J., R. BALl, B. DAVy, G. DOwnes, D. FIFE, D. Gaunt, D. Gritton, J. Ilic, A. Koehler, R. McKinley, A. Morrow, R. Northway, B. Penellum, J. Rombouts and S. Pongracic (2004): Resource evaluation for Future Profit: Part B - Linking grade outturn to wood properties. Forest and Wood Products Research and Development Corporation report Project No. PN03.3906 Resource characterization and Improvement Program. Available at: www.fwprdc.org.au pp.74pp.

Smith, D. M. (1954): Maximum moisture content method for determining specific gravity of small wood samples. U.S. Forest Service, U.S. Department of Agriculture Report, No. 2014. 8pp.

WANG, X., R. J. Ross, J. R. ERICKSON and J. B. Ligon (2000): Nondestructive evaluation of trees. Experimental Techniques 24(6): 27-29.

WILCOX, M. D. (1983): Inbreeding depression and genetic variances estimated from self- and cross-pollinated families of Pinus radiata. Silvae Genetica 32: 89-96.

Wu, H. X., A. C. Matheson and A. Abarquez (2002): Inbreeding in Pinus radiata. IV. The effect of inbreeding on wood density. Annals Forest Science 59: 557-562.

Wu, H. X., M. Ivkovic, W. J. Gapare, A. C. Matheson, B. S. Baltunis, M. B. Powell and T. A. McRae (2008): Breeding for wood quality and profit in Pinus radiata: A review of genetic parameter estimates and implications for breeding and deployment. New Zealand Journal of Forestry Science 38(1): 57-87.

Zamudio, F., R. Baettyg, A. Vergara, F. Guerra and P. Rozenberg (2002): Genetic trends in wood density and radial growth with cambial age in a radiata pine progeny test. Annals of Forest Science 59: 541-549.

Herausgeber: Johann Heinrich von Thünen-Institut. Bundesforschungsinstitut für Ländliche Räume, Wald und Fischerei.

Schriftleitung: Institut für Forstgenetik, Sieker Landstraße 2, D-22927 Großhansdorf

Verlag: J. D. Sauerländer's Verlag, Finkenhofstraße 21, D-60322 Frankfurt a. M. Anzeigenverwaltung: J. D. Sauerländer's Verlag, Frankfurt am Main.

Satz und Druck: ADN Offsetdruck, Battenberg — Printed in Germany.

(C) J. D. Sauerländer's Verlag, Frankfurt a. M., 2009 